\title{
Pedogenesis and distribution of humic substances in Pyrenean soils, France
}

\author{
M. Remaury ${ }^{1}$, A. Benmouffok ${ }^{2}$, J. Dagnac ${ }^{3}$ and Th. Gauquelin ${ }^{1}$ \\ ${ }^{1}$ Laboratoire d'Écologie Terrestre, U.M.R. 5552, Univ. P. Sabatier, 39 allées J. Guesdes, 31062 Toulouse Cedex, France \\ ${ }^{2}$ Inst. d'Agronomie, Dép. de pédologie, Univ. de Tizi-Ouzou, BP. 17 RP, 15000 Tizi-Ouzou, Algérie \\ ${ }^{3}$ CESAC, U.M.R. C 5576, Univ. Paul Sabatier, 118 rte de Narbonne, 31062 Toulouse Cedex, France
}

\begin{abstract}
Some podzolic soils near the timberline display a dark spodic horizon, underlying an ochre horizon. The underlying horizon is thought to be a relic horizon derived from a cryptopodzolic ranker. Their original distribution within the profiles was determined by humic and fulvic acid analysis. We found an increase in fulvic acids in deep ranker horizons and in the spodic horizons. A notable increase in humic acids is also observed in the dark spodic horizon. The origins of these high molecular weight organic substances in high-altitude ecosystems is discussed.
\end{abstract}

\section{Introduction}

Podzols are soils which evolution is mainly related to climate and to the presence of a raw acid humus with a slow decomposition. They are distinctly differentiated in three basic soil layers or horizons: under the holorganic layer we find an organo-mineral horizon $\mathrm{A}$, then a faded horizon $\mathrm{E}$. In depth, one or more spodic horizons B contain an accumulation in organic and/or mineral amorphous elements. Typical modal podzols contain essentially an ochre spodic horizon, BPs, rich in fulvic acids and in amorphous aluminum, overlaid by an another spodic horizon, $\mathrm{BPh}$, developed subsequently, which contains relatively more amorphous iron and humic acids. Some Pyrenean soils display unusual characteristics, close to those of beech grove soils of the Cevennes described by Warrembourg, Lossaint and Bottner [1]. In a previous study, we observed that their profiles contain two spodic horizons: an ochre BP1 horizon, rich in iron and fulvic acid, overlaying a darker chocolate colored BP2 horizon, rich in aluminum and humic acids [2]. Arctic spodosols with an inverted horizon sequence (Bs overlying Bhs) have been described in 1991 by Dahlgren and Marret [3]. A possible explanation for this inversion in the Pyrénées is the evolution of a cryptopodzolic ranker to a podzolic soil in which the BP2 horizon is a relic. In order to gain more understanding of this pedogenesis, we report a detailed study of the distribution of humic substances. Our objective was to gain more understanding on the podzolisation process occurring in high-altitude ecosystems in the 
Pyrénées and on the effects of anthropogenic influence and climatic factors.

\section{Study sites}

The soils were selected from the subalpine level of the Pyrénées, between altitudes of 1700 and 2200 meters. The samples were taken under vegetation mainly composed of Ericacea: Calluna vulgaris, Vaccinium uliginosum, Vaccinium myrtillus and Rhododendron ferrugineum. Four cryptopodzolic rankers were chosen on the Ariege and Aude side of the Col de Pailhère [4]. These soils were found on schist substratum. Samples of four representative podzolic soils were taken in the Massif du Néouvielle (Estibère Valley) in the Hautes-Pyrénées, and the Massif du Carlit, in the Pyrénées-Orientales. The bedrock is constituted mainly of igneous rock. The podzol samples were taken near the timberline, in a pine forest dominated by open groves of Pinus uncinata, localized on rocky ridges where they have found a favorable growing season.

\section{Materials and Methods}

The cryptopodzolic rankers of the Col de Pailhère were taken every $5 \mathrm{~cm}$ depth, because the visual uniformity of the profiles. The more evolved podzolic profiles were extracted by horizon and identified between igneous lumps in accordance with their color and their structure. Humus types were identified according to the classification of Jabiol et al. [5], taking into account the $\mathrm{pH}, \mathrm{C} / \mathrm{N}$ ratio and saturation percentage.

Organic carbon was determined by the Anne method (modified by the ORSTOM); nitrogen by the Kjedahl method (Aubert, [6]). Saturation percentage was calculated using an atomic absorption spectrophotometer to measure $\mathrm{K}$, $\mathrm{Ca}$ and $\mathrm{Mg}$ cations, after their extraction with $\mathrm{NaCl} \mathrm{N}$. Cation exchange capacity was determined by measuring $\mathrm{Ca}$ in the remains after saturation with $\mathrm{CaCl}_{2}$, washing with alcohol then percolation with $\mathrm{NaCl} \mathrm{N}$.

All analytical data refer to the fine earth fraction ( $<2 \mathrm{~mm}$ ) collected by sieving: texture was determined by the Robinson pipette method according to Stocke's law after elimination of the organic matter with $\mathrm{H}_{2} \mathrm{O}_{2}$ then dispersion with sodium hexametaphosphate. Free iron and aluminum in the cryptopodzolic soils were measured by the method of [7], by heat extraction $\left(60{ }^{\circ} \mathrm{C}\right)$ with Tamm reagent $(\mathrm{pH}=$ 3.2) in the presence of sodium dithionite followed by centrifugation. Iron and aluminum phases were extracted from the other soils with Tamm reagent adapted by Schwertmann in [8]. In both cases, the measurements were made with an atomic absorption spectrophotometer.

Organic acids were extracted by sodium pyrophosphate $(0.1 \mathrm{M}, \mathrm{pH}=10)$ then measured by Mohr's salt after exposure to sulfuric acid. This extraction procedure enables separation of humic acid, which precipitate in an acid medium, whereas fulvic acids are soluble in this medium [6].

\section{Results}

Results in table I are expressed by the average data of the four podzolic soils and the four cryptopodzolic soils.

Table I. Physico-chemical data of the cryptopodzolic and podzolic soils. FE: Fine-Earth fraction; Ext. P: Extraction Percentage; HA: Humic Acid; FA: Fulvic Acid.

\begin{tabular}{|c|c|c|c|c|c|c|c|c|c|c|c|c|}
\hline Horizons & $\begin{array}{c}F E \\
\%\end{array}$ & $\begin{array}{l}\text { Clay } \\
\% T E\end{array}$ & $\begin{array}{c}p H \\
-\end{array}$ & $\begin{array}{c}\text { Base sat. } \\
\%\end{array}$ & $\begin{array}{l}C \\
\%\end{array}$ & $\begin{array}{c}C / N \\
-\end{array}$ & $\begin{array}{c}\text { Ext. } P . \\
\%\end{array}$ & $\begin{array}{l}H A \\
\% \circ\end{array}$ & $\begin{array}{l}F A \\
\% \circ\end{array}$ & $\begin{array}{c}H A / F A \\
-\end{array}$ & $A l$ & $\begin{array}{c}F e \\
m e q / 100 \mathrm{~g}\end{array}$ \\
\hline \multicolumn{13}{|c|}{ Cryptopodzolic Ranker } \\
\hline $\mathrm{OH}$ & 65 & 23 & 4,5 & 19 & 18 & 18 & 46 & 2,1 & 6,1 & 0,34 & 3 & 14,2 \\
\hline $\mathrm{OH} / \mathrm{A}$ & 60 & 20 & 4,6 & 13 & 11 & 20 & 50 & 0,5 & 4,9 & 0,10 & 5 & 15,3 \\
\hline$A / B$ & 58 & 16 & 4,9 & 6 & 11 & 20 & 85 & 1,0 & 8,3 & 0,12 & 8 & 15,4 \\
\hline BC & 44 & 15 & 5,1 & 5 & 7 & 20 & 99 & 0,4 & 6,5 & 0,06 & 7 & 14,7 \\
\hline \multicolumn{13}{|c|}{ Podzolic Soil } \\
\hline $\mathrm{OH}$ & 97 & 39 & 4,2 & 32 & 25 & 14 & 26,2 & 19,5 & 1,34 & 45 & & \\
\hline$A$ & 91 & 17 & 4,2 & 17 & 13 & 24 & 23 & 20,4 & 10,6 & 1,92 & 29 & 86 \\
\hline$E$ & 70 & 13 & 4,4 & 11 & 4 & 23 & 40 & 6,7 & 7,7 & 0,87 & 38 & 150 \\
\hline BP1 & 61 & 5,8 & 4,8 & 5 & 4 & 25 & 54 & 6,7 & 15,5 & 0,43 & 117 & 195 \\
\hline BP2 & 66 & 9 & 4,8 & 3 & 7 & 22 & 76 & 18,1 & 36,2 & 0,50 & 207 & 175 \\
\hline $\mathrm{BC}$ & 44 & 5,6 & 4,8 & 3 & 3 & 20 & 69 & 7,9 & 13,5 & 0,58 & 103 & 50 \\
\hline
\end{tabular}


The Col de Pailhère soils, about $40 \mathrm{~cm}$ deep, have barely differentiated horizons. Nevertheless, we could distinguish by analysis two main organomineral distinct horizons (Tab. I). The upper one is an organo-mineral horizon from 5 to $15 \mathrm{~cm}(\mathrm{OH} / \mathrm{A})$, fibrous and matted with roots. The humus is a moder type, with $\mathrm{pH}$ around 4.5 and $C / N<20$. The A/B horizon beneath is thicker, with a low saturation percentage in the clay-humic complex $(S / T<20 \%)$. It shows a notable accumulation in aluminum. The amount of extracted organic acids content was high: $46-99 \%$. Fulvic acids were more abondant than humic acids, reaching $74-94 \%$ of the organic acids extractable with pyrophosphate (Fig. 1). In the more evolved cryptopodzolic soils, a thin ochre horizon, analysed with the A/B horizon, extended above the schist pavement.

Podzolic soils of the Carlit and Néouvielle massifs are about $60 \mathrm{~cm}$ deep. In their upper zone they show three holorganic horizons: $\mathrm{OL}, \mathrm{OF}$ and $\mathrm{OH}$, the latter having a variable thickness and gradual transition to the underlying organo-mineral A horizon. Humus was a moder type. The $C / N$ ratio was higher than in cryptopodzolic soils $(20<C / N$ $<25$ ). An eluvial horizon E, often barely differentiated, was underlaid by two spodic horizons characterised by an accumulation of amorphous products. The ochre horizon BP1 contained more extractable iron and more fulvic acids. In the underlying BP2 horizon, the percentage of organic carbon and humic acids increased. It showed the highest amount of extractable aluminum. The most noteworthy features were the high extraction yield of the BP2 horizon notably for humic acids. The humic acid/fulvic acid ratio (HA/FA) increased in the deep horizon (Fig. 1).

\section{Discussion}
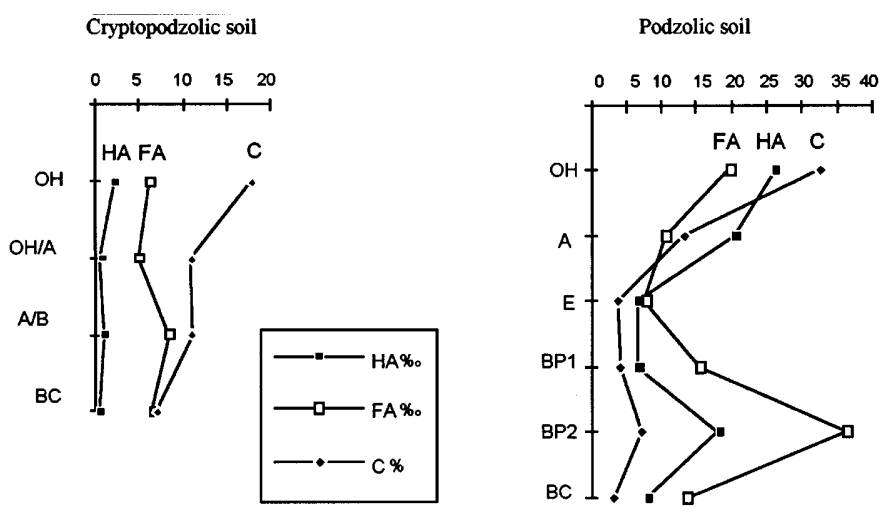

Figure 1. Carbon (C\%), humic (HA\%) and fulvic acid (FA\%०) distribution in the cryptopodzolic and podzolic soils.
Podzolization in subalpine rankers is not readily apparent. Nevertheless, it can be detected visually by the appearance of a B ochre horizon at the base of the profile. It can also be detected systematically by analysis of free-aluminium and fulvic acids. It is not clear why the evolution of the soil does not drive the formation of the $\mathrm{BPh}$ horizon, situated upper a B ochre, where organic acids should be polymerised into humic acid form. In fact, assuming that a cryptopodzolic ranker evolves into a podzolic soil, we observed in this last soil an unexpected polymerisation in the BP2 horizon, just under the $\mathrm{B}$ ochre horizon. To gain more insight on this process, we need further information on factors influencing the polymerisation of organic acids into humic acids.

Two processes could be involved. The first involves the increase of the cation/anion ratio due to the biodegradation of anions in the spodic horizon. The second one is the catalytic action of hydrates, especially free iron (ferric). Indeed, since they are most abundant in the BP ochreous level, as we observed in our podzols, they cannot readily account for the levels of humic acid observed and the deep formation of BP2.

We can here rather emphasize the role of extractable aluminum in lowering the mineralisation. This process, known in the case of Andosoils, has been reported by numerous authors. This could explain the increase in organic matter and the strong polymerisation of organic acids, as well as the black color of the deep relic horizon.

\section{Conclusion}

The distribution of humic substances in podzolic soils should be viewed in the light of the iron and aluminium phases. Further studies of the origin of high molecular weight organic substances is expected to throw more light on the podzolisation process. The influence of a change from a heath-lawn to a forest ecosystem due to anthropogenic activities and climatic changes will be investigated.

\section{References}

1. Warrembourg, F. R.; Lossaint, P.; Bottner, P. Bull. Ass. Fr. Étude du Sol 1973, 1, 49-62.

2. Remaury, M.; Gauquelin, T. H.; Dagnac, J. Ecologie 1998, 29(1-2), 187-192.

3. Dahlgren, R. A.; Marret, D. J. Soil Sci. Soc. Am. J. 1991, 55, 1382-1390.

4. Benmouffok, A. Thèse $3^{\circ}$ Cycle, Univ P Sabatier, Toulouse, 1987; pp 1-158.

5. Jabiol, B.; Brethes, A.; Brun, J. J.; Ponge, J. F.; Toutain, F. Rev. For. Fr. 1994, XLVI, 2, 152-166.

6. Alexandrova, L. N. Sov. Soil Sci. 1967, 7, 903-913.

7. Duchaufour, P. H.; Souchier, B. Sc. Sol 1966, 1, 17-29.

8. Bonneau, M.; Souchier, B. Masson 1979, 32-33. 